\title{
Learning Skills and Difficulties Encountered by Students During Acquisition of a Foreign Language for Specific Purpose
}

\author{
Enkela Dalipi, \\ University of Tirana, \\ Facolty of Foreing Languages, Tirana, Albania
}

\begin{abstract}
Through this research we are going to analyze the learning skills, thus competencies needed by students during the learning process and acquisition of a foreign language of specific purpose. The purpose of such a research is not only to identify difficulties they encounter during the learning process but also to introduce special techniques and strategies for a specific teaching process aiming at enhancement of communicative competence as primary goal of teaching/learning process. The applied method is that of survey (40 hours of study time). We have put in evidence and made remarks of the most common difficulties for students based on an assessment table. In the second part of the research, based on survey results, there are presented teaching suggestions and techniques which help students to overcome obstacles and guide them to acquire learning skills to the final end of acquisition of specialized communication competence. Besides the theoretical part there are presented practical aspects of didactic activities related to the analyzed skills.
\end{abstract}

Keywords: Skills, competence, teaching, learning, language for specific purposes, micro skills, macro skills.

\section{Introduction}

Foreign language for specific purposes is part of the University curricula in Albania. Although such teaching experience has been developed since many years, there are still complex issues as it is difficult to establish a separation line between study and acquisition of foreign general language and specific sector language.

Besides four basic language skills known as macro skills (reading, listening, speaking and writing) student who study a foreign language for specific purposes must acquire other skills which can be defined with the term micro skills such as: reading and understanding of a text of a language for specific purposes, use of vocabulary, acquisition of new specific lexis, work in library, preparation for examination, management of a studying method, systematic notes keeping, text briefing, improvement of memorizing capability, formulating of hypothesis on understanding a definition, provision of new techniques of research, preparation and presentation of a report, etc. These skills can be used for learning in general a foreign language but in the framework of the foreign language for specific purposes they are even more specific.

What are actually the difficulties encountered by students during acquisition of a foreign language for specific purposes?

To answer the above question, we are introducing results obtained through survey as explained below:

\section{Survey of difficulties related to learning skills.}

In order to have an insight and analyze the difficulties of students in acquiring skills to learn a foreign language for specific purposes we have implemented the method of survey.

The focus group are students of first year of the Medicine Faculty, University "Zoja e Këshillit të Mirë", in Tirana.

Their language profficiency is $\mathrm{B} 1{ }^{1}$.

\footnotetext{
1 Language Proficiency as per Common European Framework of Reference for Languages (CEFR)
} 
Used text "Italian for doctors".

Duration of survey: 40 study hours.

Number of students: 40 (20 for each group of the same level).

The goals of utilization of method: Obtain information on, and identify the difficulties of students in acquisition of foreign language of for specific purposes, in medical field. More precisely, the target of this survey is to define the difficulties met during the learning process.

\section{Survey methodology:}

We prepared a table with study skills which are required for the acquisition of the Italian medical language.

Table 1.

\section{Survey Table to Put in Evidence Difficulties During the Learning Process}

\begin{tabular}{|c|c|c|c|}
\hline \multicolumn{4}{|l|}{ Reading and understanding the textt } \\
\hline Fluent reading & present & \multicolumn{2}{|l|}{ is not present } \\
\hline Understanding of text & $\begin{array}{l}\text { Understands and } \\
\text { expresses concepts in } \\
\text { Italian. }\end{array}$ & $\begin{array}{l}\text { Understands but has } \\
\text { difficulties in expression of } \\
\text { concepts }\end{array}$ & $\begin{array}{l}\text { Does not understand } \\
\text { concepts }\end{array}$ \\
\hline \multicolumn{4}{|l|}{ Capability to perform text briefing } \\
\hline $\begin{array}{l}\text { Distinguish primary information from } \\
\text { secondary one }\end{array}$ & \multicolumn{2}{|c|}{ Capability to perform text briefing } & $\begin{array}{l}\text { Difficulty to perform text } \\
\text { briefing }\end{array}$ \\
\hline \multicolumn{4}{|l|}{ Capability to prepare a written report } \\
\hline Use of medical terms & Not used at all & Used with difficulty & Used easily \\
\hline $\begin{array}{l}\text { Providing arguments to } \\
\text { support/contradict a given thesis }\end{array}$ & $\begin{array}{l}\text { Do not provide arguments } \\
\text { at all }\end{array}$ & $\begin{array}{l}\text { Difficulties in providing } \\
\text { arguments }\end{array}$ & Provide easily arguments \\
\hline Orthography of the word & Correct & \multicolumn{2}{|l|}{ Wrong } \\
\hline Structure & Correct & \multicolumn{2}{|l|}{ Wrong } \\
\hline Form of active/passive verbs & Correct & \multicolumn{2}{|l|}{ Wrong } \\
\hline \multicolumn{4}{|l|}{ Capability to present a report } \\
\hline Types of presentation & $\begin{array}{l}\text { Qualitative \& independent } \\
\text { thinking }\end{array}$ & \multicolumn{2}{|c|}{ Simple/Mechanic/no independent thinking } \\
\hline Presentation methods & With Power Point & \multicolumn{2}{|l|}{ Without Power Point } \\
\hline
\end{tabular}

\subsection{Reading and understanding the text.}

It resulted out of the survey that more than $50 \%$ of the students had difficulties in reading and understanding of a new text. $30 \%$ of them understood the concepts of the text but had difficulties in expressing them in Italian language; $20 \%$ of the students were not able to give the correct answer to questions related to understanding of the text.

\footnotetext{
${ }^{1}$ Forapani D., L'italiano per i medici, Alma Edizioni, Prill, 2004.
} 


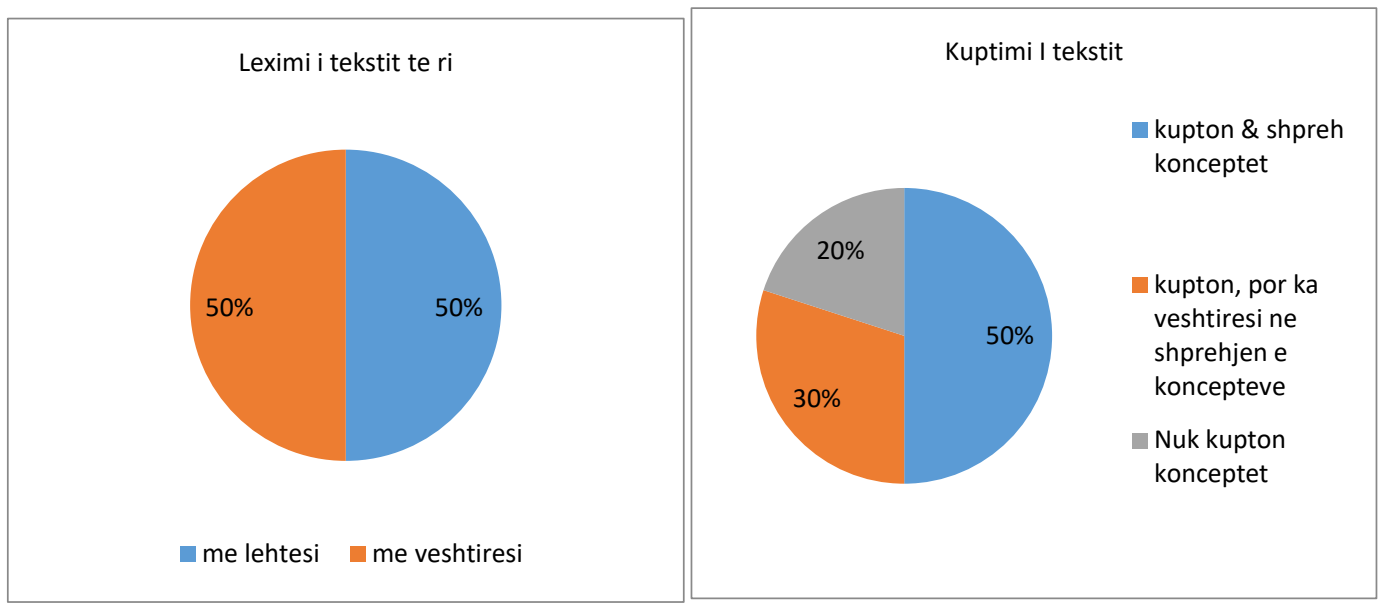

\subsection{Capability to synthesize}

It resulted out of the survey that only $40 \%$ of the students were in possession of good skills to synthesize a relatively long text. $60 \%$ of them had difficulties in determining the level of priorities of information.

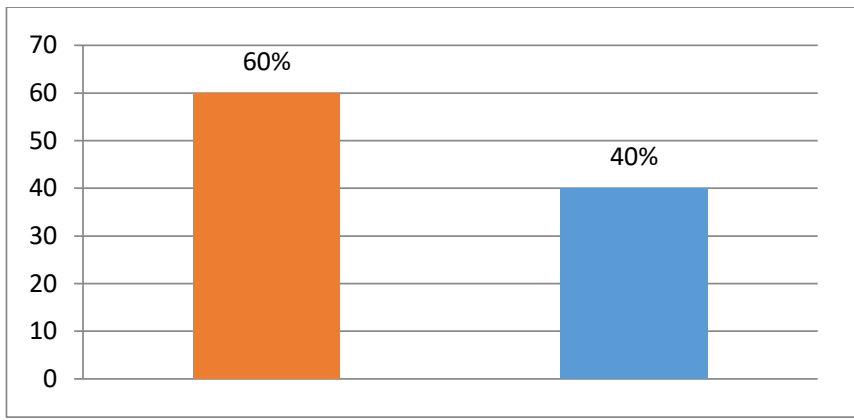

\subsection{Capability to prepare a written report}

It resulted out of the survey that $50 \%$ of the students made mistakes in the orthography of words and terms. $30 \%$ of students used active verbs instead of passive ones. $20 \%$ of them did not follow the structure according to the form:

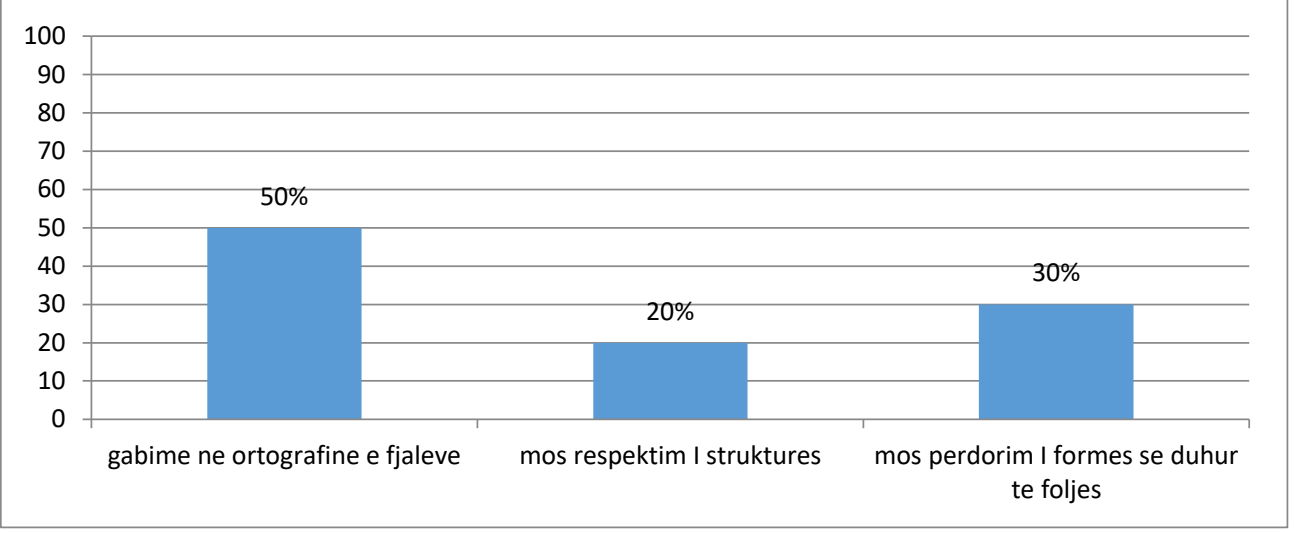


introduction-development of arguments-conclusions.

\section{Capability to present a report}

Communication in language for specific purposes is expression of opinion in a discipline related to the referring subject through the communication scheme of that discipline. Students must gain knowledge and able to manage the way of thinking of the experts of the discipline, subject to language studying

It resulted out of the survey that $60 \%$ of the students presented their work simply by reading it and had difficulties in giving an independent opinion, especially in the concluding part. Although they had acquired the medical terminology, they had difficulty namely in giving arguments to oppose or support a certain thesis.

Power Point Presentation resulted more qualitative and interesting (40\%) against the simple presentations.

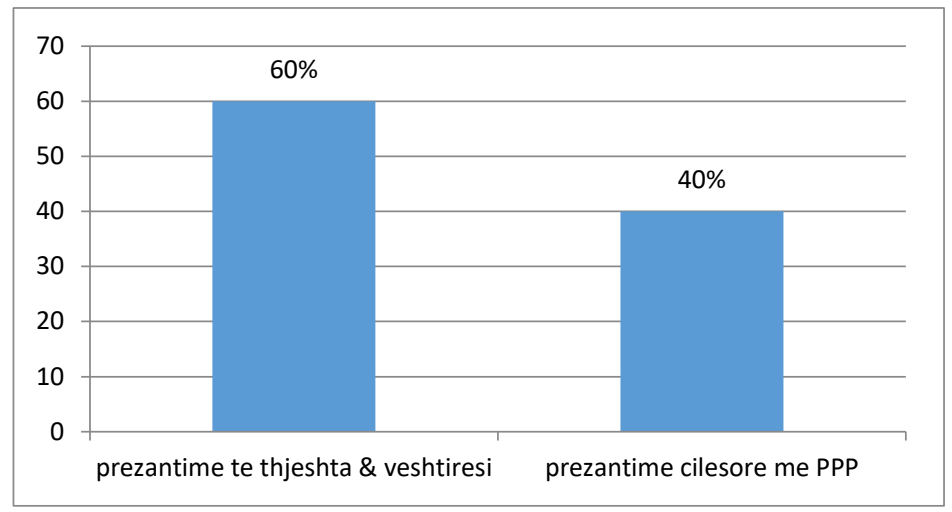

\section{Teaching techniques and didactic activities related to learning skills.}

Due to the results obtained through survey method which brought into light difficulties encountered by students during the learning and acquisition process of a foreign language for specific purposes we are going to analyze in a more detailed manner the learning skills by introducing theoretical suggestion and teaching techniques in function of acquiring not only linguistic skills but communicative ones as well.

\subsection{Capability to read and understand a text in a foreign language for specific purposes}

Didactics of foreign language for specific purposes emphasizes primarily the skill of reading or understanding the text, as reading means understanding as well. The task of a foreign language teacher is to introduce a text that is meant to speak, be read and reread guiding the student to fully ascertain it. By acquiring reading strategies, it becomes easier for the student the access to very difficult texts in various areas. This is no more in function of deciphering texts in linear way but to perceive their meaning based also on linguist indicators (title, content) or extra linguistic indicators (images, signs, diagrams), typical for languages for specific purposes.

Reading does not consist in a simple perception and understanding all words from a text as it is a reason guided activity through which the readers seeks answers. Differently from the past when reading process was considered a skill to distinguish letters and words where words were used to construct a sentence, sentences were used to make paragraphs to make long speeches, nowadays it is as a vivid organic intellectual and thinking process, always in action, where the reader achieves more the understanding of the text than reproducing its words. It is not about a thinking function but a result from many factors defined more appropriately as skills. ${ }^{1}$

In order to study a text of foreign language of specific purpose it is required to use special techniques by which is made possible the determining of principal ideas organized in a critical and organic manner. Any new received information is not

${ }_{1}^{1}$ B.M. Brazon, Il processo del leggere. Liviana, Padova 1974. Fq 137 
simply added to those we already possess but it offers new tools of understanding, thus creating a new asset in the individual knowledge.

The Chart below presents the consecutive line of actions to be followed during the reading-learning process:

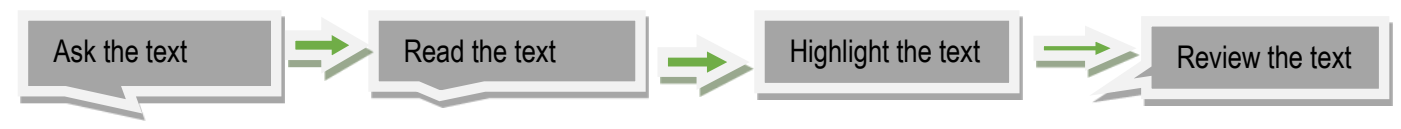

\subsection{Capability to summarize in a synthetic way a text of language for specific purposes}

Making a synthesis of a text in a given language of specific purpose involves not only just skills of linguistic nature but also the logical nature. Such activity needs shortening of text in quantitative terms and keeping unchanged the communicative function. It also requires that the semantic content of the text is not lost.

The teacher of foreign language for specific purposes must guide students by giving suggestion the required techniques to summarize a text. Students needs practicing to acquire te following skills:

* Read the text by starting with the general elements and continuing with the more specific ones,

Or figuratively from macroscope to microscope;

* Understand different parts of the text;

* Understand the logic-pragmatic relationship between various parts;

* Understand its main target;

* Define priority levels between information provided by text by distinguishing the essential from secondary ones in function of the priority goal of thoroughly understanding the;

* Reformulate the text by defining relationship between different parts and by amending it time after time;

Below are provided some didactic activities which can be utilized to support reading and text summarizing skills in a language for specific purposes.

\section{Activity 1:}

Read the title and make remarks on the general understanding of the text.

\section{Activity 2}

After having read the text, put in two columns sentences which outline the logical reasoning part and those related to the explanatory part.

\section{Activity 3}

Read the text and underline the specific information found in it.

\section{Activity 4}

Define a level of priority for information given in the text by distinguishing the essential from secondary to support the priority goal previously identified.;

\section{Activity 5}

Read the part and underline the key words of each paragraph.

\section{Activity 6}

Underline logic/pragmatic relationship between various parts of the text.

\section{Activity 7}


Read the part in 2 minutes and summarize in the form of synthesis.

\subsection{Capability to write a language for specific purposes}

Among the various didactic teaching/learning activities to learn foreign language for specific purposes, reading activities are important. These activities are suggested to take place at the end of any didactic session as it is believed that linguistic competences (Morphosyntax, lexical, textual rules) and those related to the content are acquired.

Teachers must guide students by giving them pertaining suggestions and standard, typical models for a given language for specific purposes and only after that students can be independent in performing a certain type of activity.

Therefore, after reflection and planning, students must keep notes on the arguments they plan to treat and ideas to present. They cannot write in a clear manner if their ideas are confused or if they have insufficient knowledge on the selected arguments. After this process, there are structured the kept notes and is prepared the work design. It starts with its composing and during the first review students must check if the coherence and cohesion with text is met. Also they must control the lexical choices by selecting the most appropriate terms and verify the orthography with help from vocabulary. It is suggested to use specific terms of the discipline subject to study. Students must pay equal attention to different parts of the text and may use expressions and linking elements which bring into light the pragmatic value of paragraphs by listing in a coherent manner and by avoiding repetition. Thus it is of essence that ideas are not only accurate and expressed though a correct linguistic manner but also to comply with a structure that can be considered conventional in a given discipline.

Besides suggestions, teachers can offer to students through didactic activities standard text models of the specific sector (reports, minutes, description of experiments etc) where are underlined those aspects related to the organization of text and utilization of formal elements that are typical for a given language for specific purposes.

Below we are providing some didactic activities examples which aim at acquisition of capabilities to compose and write a text in different languages for specific purposes..

\section{- Suggestions on performing didactic activities}

In order to have a higher level of independence students can be provided with sufficient information data on the content and goal of the text they have to write. There can be carried out didactic activities which involve the following comparative tasks: concept/definition, problem/solution, comparison/distinguish, cause/consequence, proposal/support with arguments, purpose/activity and at the end drawing conclusions.

Another technique would be the distribution of various texts of scientific-professional nature where linking elements are missing (interfix, expressions). It is asked from students to put together sentences by placing the missing words in proper position or after there are given different sentences which mean same concept, it is requested from students to put them together in composed sentences or paragraphs. This technique enables students to create and write text by following the coherence and cohesion criteria as two crucial features of a written text.

By fulfilling the suggestions and provided models students can gradually gain complete independence and are capable to compose and write a text professionally.

\subsection{Capability of presenting a report}

The presentation of a report or a given assigned task needs possession of specific skills which can be acquired through special didactic instructions.

The initial step for the students is to structure the argument. Questions are made such as: What do listeners have to or want to listen about the selected argument? How much new information they have to get?

Secondly, there is defined the purpose of the presentation: (what is the most crucial and important point to be understood?) 
Thirdly, it is necessary to prepare a synthetic schedule which will include the essential topic and auxiliary ones. For this purpose it is needed to collect valid auxiliary information. (What information supports better the main topic? What information can attract more the attention of listeners?...).

Fourthly, there is needed to select a structure convenient for the presentation. For example in the case of describing experiments there can be followed this scheme: introduction, materials, procedures, results, discussions.

Fifthly, selection of convenient audiovisual supporting tools which have an impact in attracting of listeners' attention can reflect easily the presented arguments and facilitate their understanding.

Preparation of introductory part is very crucial as listeners have the possibility to get acquainted since the start with essential information to get an understanding of the argument. Taken the fact that languages for specific purposes are characterized by many definitions it is of most importance to explain them during the introductory part of presentation. For such purpose, there can be used techniques to get familiar with specific terminology through various modalities of utilization of linguistic acts.

The conclusion part must bring again in a summarized manner the essential elements to draw conclusions, by leaving the possibility of a treating an argument in another moment or figuratively said by closing a door but opening a window.

\section{Conclusion}

Learning and acquisition of a foreign language for specific purposes is difficult and is a challenge for both actors of the education process: the student and the pedagogue. On the other hand, such difficulties turn to be strong points resulting to a mutual interrelation between the teacher who is competent in foreign language and has general knowledge on the specialized discipline and the student who is competent in a given specialized discipline but lacks linguistic knowledge. This situation has an impact on enhancing the didactic communication teacher-student giving birth to what is called collaboration didactics.

The teacher of foreign language for specific purposes must create, through his educational and didactical activities, communicative situations and elaborate didactic strategies to facilitate reduction of difficulties encountered by students during the process of learning language for specific purposes. The final outcome is a type of teaching aiming at enhancement of communicative competence in different scientific-professional situations.

The used methodologies should be in compliance with the didactic goals which must ensure harmony between language, micro language objectives and communication in foreign language for specific purposes objectives.

During the teaching of foreign languages for specific purposes, the teacher must work by making use of didactic activities in function of integrated use of macro capabilities and micro capabilities. The language skills are generally of a transversal type as they are not specific for a given language for specific purposes, but after acquired in one of them, they can be transferred to other languages for specific purposes. Thus the acquisition of a of the foreign language becomes a tool of scientific and professional cohesion for the linguistic communities all over the world.

Bibliografia

[1] Ballarini E. Didattica delle Microlingue, Laboratorio Itals, Universita' 'Ca'Foscari', Venezia 2002.

[2] Balboni P.E Le microlingue scientifico-professionali, Natura e insegnamento, UTET Libreria Srl, Torino 2004

[3] Barzoni B.M. Il processo del leggere, Liviana, Padova 1974.

[4] BuehI D. Classroom Strategies for Interactive Learning', International Reading Associaton USA, 2001.

[5] Caimi V. ESP-LSP: un modello teorico-applicativo per una didattica della microlingua, Lingue di specializzazione e il loro insegnamento- problemi teorici e orientamenti didattici, Vita e Pensiero, Milano, 1990.

[6] Cambiaghi B. Didattica della Ricezione del testo microlinguistico, në 'Le lingue di specializzazione e il loro insegnamento, Vita e Pensiero, Milano, 1985. 
[7] Candlin C.N., Kirkwood J.M. e Moore H.M. Study skills in English: teoritical issues and practical problems, në Mackay e Mountford, 1978.

[8] Ciliberti A. L'insegnamento linguistico per scopi speciali, Zanichelli,Bologna, 1998.

[9] Forapani D. l'italiano per i medici' Alma Edizioni, Firenze, 2004.

[10] Deva F. I processi di apprendimento della lettura e della scrittura, La nuova Italia, Firenze 1982.

[11] Grassisli B. Per una metodologia della lettura, Minerva Italica, Bergamo 1979.

[12] Porcelli G. Le lingue di specializzazione e il loro insegnamento. Problemi teorici e orientamneti didattici, UTE Libreria, Torino, 1990 